\title{
The Effects of Green Transformational Leadership on Adoption of Environmentally Proactive Strategies: The Mediating Role of Green Engagement
}

\author{
Stanley Y. B. Huang ${ }^{1}$, Chih-Wen Ting ${ }^{2, *}$ and Ming-Way Li ${ }^{3}$ \\ 1 Department (Program) of Financial Technology, School of Financial Technology, Ming Chuan University, \\ Taipei 11162, Taiwan; yanbin@mail.mcu.edu.tw \\ 2 Department of Tourism Management, Nanhua University, Chiayi County 62249, Taiwan \\ 3 Department of Marketing and Logistics Management, College of Business Management, Chihlee University \\ of Technology, New Taipei City 220305, Taiwan; vincent@gm.chihlee.edu.tw \\ * Correspondence: cwting@mail.nhu.edu.tw
}

Citation: Huang, S.Y.B.; Ting, C.-W.; Li, M.-W. The Effects of Green Transformational Leadership on Adoption of Environmentally Proactive Strategies: The Mediating Role of Green Engagement. Sustainability 2021, 13, 3366. https:// doi.org/10.3390/su13063366

Academic Editor: Chris Shiel

Received: 4 February 2021

Accepted: 12 March 2021

Published: 18 March 2021

Publisher's Note: MDPI stays neutral with regard to jurisdictional claims in published maps and institutional affiliations.

Copyright: (c) 2021 by the authors. Licensee MDPI, Basel, Switzerland. This article is an open access article distributed under the terms and conditions of the Creative Commons Attribution (CC BY) license (https:// creativecommons.org/licenses/by/ $4.0 /)$.

\begin{abstract}
To explore key antecedents of environmentally proactive strategies, this work uses upper echelons theory to examine a novel concept-green engagement with its antecedents (green transformational leadership) and consequence (environmentally proactive strategies). This work employed a potential growth curve model with 501 CEOs and top management teams of technology manufacturing businesses in Greater China at three times over eight months to analyze the theoretical model. The results of this work showed that the green transformational leadership of CEOs significantly predicts positive changes of green engagement of top management teams, which consequently predicts environmentally proactive strategies. These findings provide theoretical insights for the field of environmental development that can advance the literature on environmentally proactive strategies.
\end{abstract}

Keywords: green transformational leadership; green engagement; environmentally proactive strategies; Greater China

\section{Introduction}

Eenvironmentally proactive strategies (EPSs) have been confirmed as an important source of firm performance and competitive advantage [1-3]. EPSs denote the strategies that corporates employ to decrease negative influences on the natural environment caused by corporate activities [4]. Past studies proposed that exploring key antecedents of EPSs is an urgent need because it can effectively cope with environmental problems $[5,6]$. However, previous studies on antecedents of EPSs have only two streams to focus on this field, including social and organization factors [4]. This work employs upper echelons theory to propose a theoretical model that green transformational leadership (GTL) of CEOs can predict corporates' adoption of EPSs through mediating role of green engagement (GE) of top management teams (TMTs). The upper echelons theory [7] can explain the theoretical framework in this study because characteristics (values) of CEOs and TMTs can affect corporates' strategic choices (e.g., EPSs) and Leadership styles (e.g., GTL) of CEOs are confirmed as key characteristics of CEOs [8]. Besides, GE is an important characteristic (value) of TMTs, because GE is one kind of value for environmental protection. GTL refers to that a transformational leader turns followers towards corporates environmental responsibilities [9]. This work employs GTL of CEOs as an antecedent of EPSs because the past research has missed the important role of GTL [4] to cause a literature gap.

Kahn's (1990) [10] engagement theory proposes that individuals actively drive their selves to achieve a role performance through putting cognitive, emotional, and physical resources on jobs. That is to say, an individual puts head (cognitive resources), heart (emotional resources), and hands (physical resources) into a role performance. However, relatively few studies focus on how this concept can be defined theoretically and measured 
empirically [11,12] because previous studies often define engagement from practitioner literature and consulting firms. In particular, the previous research also developed antecedents and outcomes of engagement based on past empirical studies rather than Kahn's (1990) engagement theory [13]. An important contribution is to clarify engagement theory as cognitive engagement, emotional engagement, and physical engagement. This work proposes a novel concept- " green engagement" with green cognitive engagement, green emotional engagement, and green physical engagement based on Kahn's work (1990). Transformational leadership is a key source of engagement because it guides interpretive schemes of individuals to fit organizational interpretive schemes, which let the individuals obtain meaningfulness from their job. Meaningfulness has been confirmed as a key antecedent of engagement [10]. Besides, the past research has paid attention to the direct effect of social factors and organizational factors on EPSs, but little research opens the black box on how GTL of CEOs affect EPSs by GE of TMTs. The GE is an important characteristic (value) of TMTs, and the characteristics (values) of the TMTs can significantly influence corporates' adoption of strategies based on upper echelons theory [14]. Moreover, TMTs have the legitimacy to launch corporates' diverse resources [15], and GE of TMTs should be consistent with the strategic objectives of corporates, supporting the antecedent role of GE for EPSs.

In sum, this work used a potential growth curve model to examine how the effects of GTL of CEOs at the initial time (Time 1) can influence the positive changes of GE of TMTs, which consequently can influence positive changes of adoption of EPSs. Because most past studies of EPSs were cross-sectional surveys [1,4-6] and rare empirical evidence on if the effects of GTL on EPSs are strengthened, weakened, or stable over time. This work examined 501 corporates with its CEOs and TMTs three times over six months that can handle these gaps in the literature of EPSs.

\section{Theory and Development of Hypotheses}

\subsection{Green Transformational Leadership of Chief Executive Officers and Environmentally Proactive Strategies}

Transformational leadership denotes that leaders employ idealized influence, intellectual stimulation, inspirational motivation, and individual consideration to transform followers' self-concepts to meet organizations' values [16].

GTL denotes that leaders motivate followers to achieve environmental goals and inspire followers to perform beyond expected levels of environmental performance through idealized influence, intellectual stimulation, inspirational motivation, and individual consideration [9]. First, GTL of CEOs not only employs idealized influence and inspirational motivation to shape and transform a corporate's values to meet environmental protection but also encourages actively independent thoughts and innovations to improve environmental performance [9], which in turn, causes the corporate to actively understand and deploy priorities of environmental strategy. Second, characteristics of CEOs can affect strategic choices of corporations based on upper echelons theory [7], and transformational leadership is an important characteristic of CEOs [8], supporting the antecedent role of GTL of CEOs for corporates' adoption of EPSs. Third, past research found that GTL can influence green performance [17-19], and green performance is a key source of EPSs [20,21]. Finally, a recent study also points out a possible relationship between GTL and EPSs [22]. This work proposes the following hypothesis:

Hypothesis 1 (H1). The higher levels of GTL of CEOs at Time 1 cause higher levels of corporates' adoption of EPSs.

\subsection{The Mediating Role of Green Engagement of Top Management Teams}

Kahn's (1990) [10] ethnographic research proposed engagement theory as "the simultaneous employment and expression of a person's "preferred self" in task behaviors that promote connections to work and to others, personal presence (physical, cognitive, and emotional) and active, full performances" (Kahn 1990, p. 700) [10]. Based on Kahn's 
(1990) [10] definition, this work argues that the context of engagement theory should be classified into cognitive engagement, emotional engagement, and physical engagement because an individual who puts cognitive resources into a job (e.g., I ought to work hard) to increase a role performance is not necessarily to put emotional resources into a job (e.g., I am enthusiastic for work) or put physical resources into a job (e.g., I actually work hard) at the same time. In short, the individual actively drives himself or herself to achieve a role performance through putting physical, cognitive, and emotional resources on the job [10]. In other words, an engaged individual puts his or her head (cognitive resources), heart (emotional resources), and hands (physical resources) into a job to achieve high levels of role performance. This work defines cognitive engagement as a level of focus, concentration, engrossment, and the focused intensity for a job, and this work includes research [23] for absorption as its representative variable. This work defines emotional engagement as pleasantness (feeling positive) and activation (a sense of energy) for a job, and this work includes research [24] for core affect as its representative variable. This work defines physical engagement as energy exerted per unit of time for a job, and this work includes research [25] for work intensity as its representative variable. This work further proposes three novel concepts-green cognitive engagement (absorption), green emotional engagement (core affect), and green physical engagement (work intensity). Green absorption denotes a level of focus, concentration, engrossment, and focus intensity for an environmental scheme. Green core affect denotes a positive and sense of energy for an environmental scheme. Green work intensity denotes energy exerted per unit of time for an environmental scheme.

Kahn's (1990) [10] engagement theory proposes that meaningfulness can influence individuals to invest their energies into role performance to achieve a high level of engagement. Organizational values can be transmitted from transformational leaders to their followers in terms of the behaviors considered appropriate and expected for their given role [26], and transformational leaders can transform the personal values of their followers involved in their self-images to be congruent with organizational values [27], which let followers are in harmony with their self-images [10] to perceive a higher degree of meaningfulness. Besides, a past study [28] argues that job resources can drive engagement based on job demand-resources theory [29] and job resources (e.g., coaching, workplace diversity, and social support) can be built by transformational leadership [30]. This work adds a "green" aspect to transformational leadership and engagement to provide a basic inference between GTL and green engagement. First, green organizational values (e.g., environmental scheme) can be transmitted from green transformational leaders to their followers (e.g., TMTs) in terms of the behaviors considered appropriate and expected for their given role, and green transformational leaders can transform the personal values of their followers involved in their self-images to be congruent with organizational values to perceive a higher degree of meaningfulness toward "green" aspect. Second, based on the theory of "management of meaning" [31], green transformational leaders shape the self-concept of their followers to obtain meaningfulness toward the "green" aspect. Third, GTL can increase job resources, which in turn, increases green engagement based on job demand-resources theory. Finally, a recent study also pointed out a possible relationship between GTL and green engagement [32]. As the above discussion, the GTL of CEOs can increase the GE of TMTs. This work proposes the following hypotheses:

Hypothesis 2 (H2). The higher levels of GTL of CEOs at Time 1 cause higher levels of green absorption of TMTs.

Hypothesis 3 (H3). The higher levels of GTL of CEOs at Time 1 cause higher levels of green core affect of TMTs.

Hypothesis 4 (H4). The higher levels of GTL of CEOs at Time 1 cause higher levels of green work intensity of TMTs. 
The engagement has been examined in different contexts (countries) to confirm its reliability and validity [33] and has been examined in the Greater China context with high levels of reliability and validity [34]. Besides, characteristics (values) of TMTs can influence corporates' adoption of strategic choices based on upper echelons theory [9], and GE is one kind of value for environmental protection, thus classifying the antecedent role of GE of TMTs for EPSs. For example, green absorption, green core affect, and green work intensity denote TMTs' values of an environmental scheme. Moreover, a TMT has the legitimacy to handle resources to influence strategic goals of corporates [35], and thus TMTs have high levels of GE can influence corporates' adoption of EPS. By contrast, TMTs with a low level of GE may have a low level of assimilation with environmental impacts and there is a higher chance of using resources for sustainable interest development [36]. This work proposes the following hypotheses:

Hypothesis 5 (H5). Higher levels of green absorption of TMTs cause higher levels of corporates' adoption of EPSs development.

Hypothesis 6 (H6). Higher levels of green core affect of TMTS cause higher levels of a corporates' adoption of EPSs development.

Hypothesis 7 (H7). Higher levels of green work intensity TMTs cause higher levels of a corporates' adoption of EPSs development.

\section{Methodology}

This work proposes a theoretical model (Figure 1) that is from GTL of CEOs to corporates' adoption of EPSs through mediating role of TMTs' green absorption (cognitive engagement), green core affect (emotional engagement), and green work intensity (physical engagement).

\subsection{Subjects and Procedures}

This work collected longitudinal data at three-time points (Time 1 to Time 3 ) over six months from technology manufacturing businesses of Grater China to test the potential growth curve model. This work employed sample with technology manufacturing businesses of Grater China, because not only the businesses are well known in the world but also the businesses should have green management concepts that are in line with the world. Also, this work used multiple sources of data with three-time points that can reduce common method bias [37].

This work invited 530 CEOs of technology manufacturing businesses to take part in the investigation and asked them to invite their TMTs. Of these 530 CEOs, 520 CEOs with their TMTs agreed to take part in the investigation. This work employed an anonymous questionnaire to prevent CEOs from knowing TMTs' questionnaire. After this work received the 520 samples of the CEOs' assessments about GE of TMTs and TMTs' assessments about the GTL of CEOs, ethical leadership (control variable) of CEOs, and corporates' adoption of EPSs at Time 1, this work surveyed these CEOs and TMTs again at Time 2 regarding the CEOs' assessments about GE of TMTs and TMTs' assessments about the EPSs at three months later. Because 3 CEOs were dropped out of the businesses, and 7 TMTs were reorganized, which caused this work to miss 10 samples at Time 2. This work surveyed the final data of these CEOs and TMTs six months later, and this work received 501 valid samples. This work used the lag of three months with three repeated measurements because behaviors or attitude changes should be visible at this time framework, and previous studies also used this framework to analyze the potential growth curve model [38-40]. 


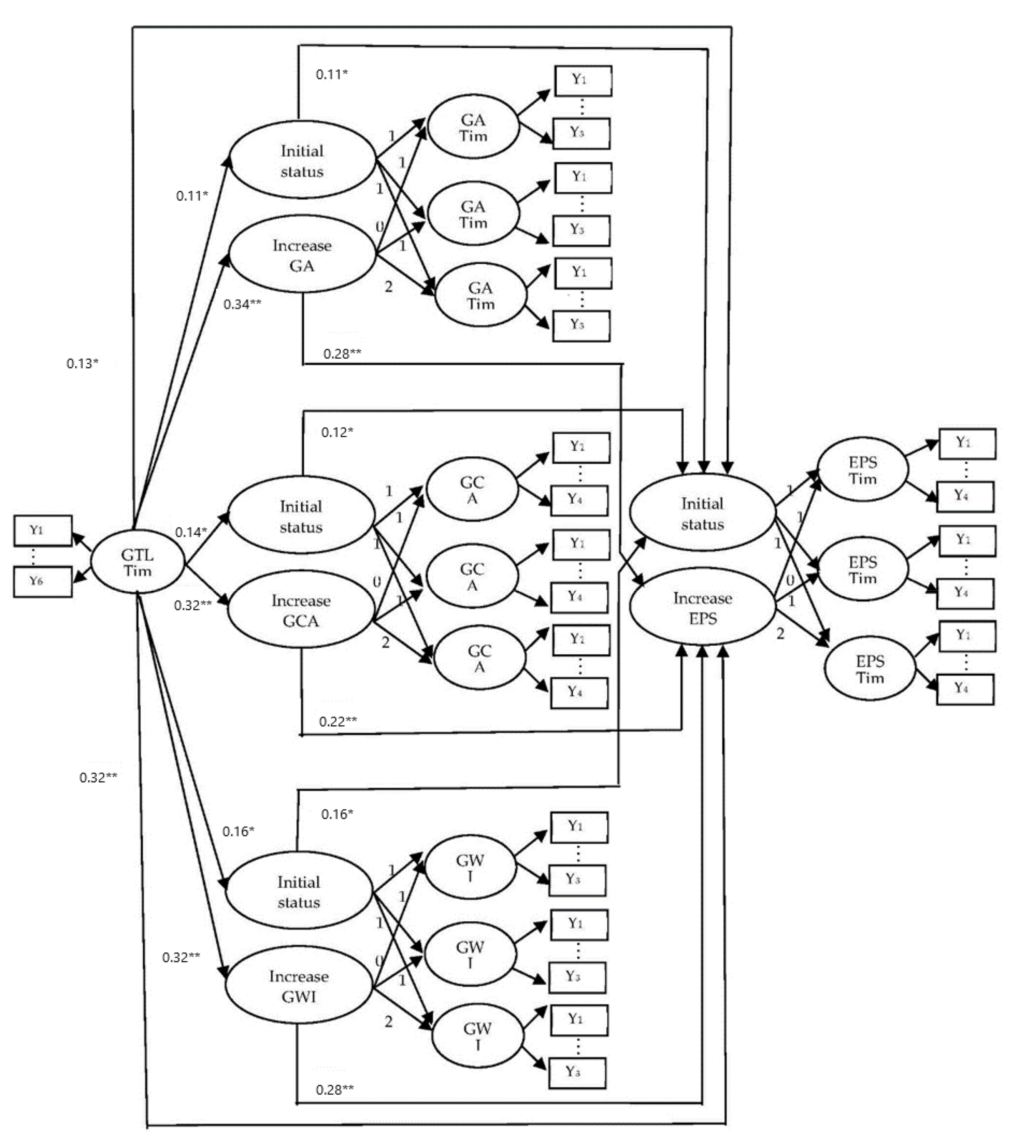

Figure 1. The potential growth curve model of this work. Note: GTL = Green Transformational Leadership; GA = Green Absorption; GCA = Green Core Affect; GWI = Green Work Intensity; EPS = Environmental Proactive Strategy. $\mathrm{Y}_{\mathrm{n}}=$ Measurement items ${ }^{*} p<0.05 ;{ }^{* *} p<0.01$.

This work got 501 usable data of CEOs and TMTs, representing a rate of $93.2 \%$. The job categories for 501 CEOs are all presidents. This work used Harman's one-factor test to confirm the common method bias [37], and the results showed that the variances of the items in this study were not distributed as one single factor instead of five factors of theoretical framework in this study, thus classifying that common method bias is not a threat in this study (please see Table 1). Besides, this work also included firm size and number of firm employees as control variables, because these variables may influence the strategic choice of corporates [41].

Table 1. Harman's One-Factor Test.

\begin{tabular}{cccc}
\hline Component & Total (Eigenvalue) & \% of Variance & Cumulative \% \\
\hline 1 (GTL) & 2.3 & 0.22 & 0.22 \\
2 (EPS) & 1.9 & 0.17 & 0.39 \\
$3(\mathrm{GA})$ & 1.5 & 0.12 & 0.51 \\
$4(\mathrm{GWI})$ & 1.2 & 0.14 & 0.65 \\
$5(\mathrm{GCA})$ & 1.1 & 0.12 & 0.78
\end{tabular}

GTL = Green Transformational Leadership; GA = Green Absorption; GCA = Green Core Affect; GWI = Green Work Intensity; EPS = Environmental Proactive Strategy.

\subsection{Measures}

All surveys were used a self-report questionnaire with a seven-point Likert, and the backward translation design of [42] was used to guarantee the translation quality.

Green transformational leadership of chief executive officers. This work referred to the popular scale of Chen and Chang's (2013) six-item scale of GTL [9] in the field of 
green management to develop new scales, because Chen and Chang's (2013) scale [9] was developed to measure the target of green innovation project rather than GTL of CEOs. These new items were filled by TMTs to evaluate the GTL of CEOs. The six new items are "My CEO leader inspires me with an environmentally friendly manner", "My CEO leader tell the environmental vision for me", "My CEO leader gets the TMTs to work together for the same environmental goals", "My CEO leader encourages me to achieve the environmental goals", "My CEO leader acts with considering environmental beliefs of TMTs" and "My CEO leader stimulates me to think about the green performance".

Green engagement of top management teams. Existing scales of engagement do not reflect Kahn's (1990) [10] engagement theory well that the degree to which an individual put his or her cognitive, emotional, and physical resources into his or her role performance [43]. Even the most popular scale of the Utrecht Work Engagement Scale (UWES) [44] does not respond well to the domain of Kahn's (1990) work [10]. For example, the items of UWES include the meaningfulness of work, but the meaningfulness is a key antecedent of engagement rather than a domain of it [10]. This work collected practices described by scholars for engagement and referred to the research of scale development [45] to develop a new engagement scale that reflected Kahn's (1990) [10] engagement theory. The goal was to measure the cognitive engagement, emotional engagement, and physical engagement for the environmental scheme. This work dug suitable existing scales to fit the three domains of engagement rather than perfect scales. In reviewing existing measures that may map Kahn's cognitive engagement, emotional engagement, and physical engagement, this work employed Rothbard's (2001) research [23] for absorption, Russell and Barrett's (1999) research [24] for core affect, and Brown and Leigh's (1996) research [25] for work intensity as the three domains of engagement. Further, this work proposes a novel concept-green engagement with green absorption, green core affect, and green work intensity. This work referred to Rothbard's (2001) research [23] for absorption to develop the three-item scale of green absorption, and the items are "At work, my mind is focused on environmental management and protection", "At work, I focus a great deal of attention on environmental management and protection" and "At work, I devote a lot of attention to environmental management and protection". The work referred to Russell and Barrett's (1999) research [24] for core affect to develop the four-item scale of green core affect, and the items are "I am enthusiastic in executing the environmental management and protection", "I feel energetic in executing environmental management and protection", "I am interested in executing environmental management and protection" and "I am proud of executing environmental management and protection". The work referred to Brown and Leigh's (1996) research [25] for work intensity to develop the threeitem scale of green work intensity, and the items are "I exert my full effort in executing the environmental management and protection", "I devote a lot of energy in executing the environmental management and protection" and "I try my hardest to perform the environmental management and protection".

Environmentally proactive strategy. This work referred to scale [4] for corporate environmental proactivity to develop the scale of EPSs. The items are "My corporate always attempt to go beyond basic compliance with laws and regulations on environmental issues.", "My corporate gives a high priority to environmental issues" "The top managers in my corporate give environmental issues a high priority" and "My corporate effectively manage the environmental risks that affect our business".

\subsection{Data Analysis}

\subsubsection{Potential Growth Curve Model}

The potential growth curve model is employed to analyze the changes of variables and how these effects can cause other variables' changes. For example, this work repeatedly measured the three-phase data to analyze the empirical data, and the potential growth curve model can capture the linear changes on TMTs' green absorption, green core affect, green work intensity, and corporates' adoption of EPSs over time. 
The factor loadings of repeated measurement constructs in the items are set up for 1 to make the intercept that can equally influence repeated measurements. The loadings from the scope of these constructs to the repeated measurements are set up for 0,1 , and 2 to measure the changes (positive) [38]. The first-factor loading is set up to be 0 because it reflects the mean of the initial measurement (Time 1) [39].

The second-order-factor is used in a potential growth curve model technique to test the significance of paths. For example, the GTL of CEOs at Time 1 was related to the initial status and the slope of TMTs' green absorption, green core affect and green work intensity, and corporates' adoption of EPSs. The initial status and the slope of TMTs' green absorption, green core affect, and green work intensity were also related to the initial status and the slope of the corporates' adoption of EPSs.

\subsubsection{Confirmatory Factor Analysis}

This work used confirmatory factor analysis to confirm the reliability and validity of GTL, green absorption, green core affect, green work intensity, and EPSs. The IBM SPSS Amos 25 was used to analyze the data. The AVE (average variance extracted) of these variables are above 0.65 . The CR (composite reliability) of these variables are above 0.74 . The RMR (<0.08), RMSEA (<0.05), GFI (>0.9), CFI (>0.9), GFI (>0.9), and NFI (>0.9) also fit well suggested by Fornell and Larcker's (1981) research [46]. Besides, all standardized factor loadings of these variables are significant. The means, standard deviations, correlation, reliability, and validity are shown in Tables 2 and 3.

Table 2. Means, standard deviations, and correlation $(\mathrm{N}=501)$.

\begin{tabular}{ccccccc}
\hline & M & S.D. & GFL & GA & GCA & GWI \\
\hline GFL & 4.59 & 0.83 & & & & \\
GA & 4.79 & 0.79 & 0.43 & & & \\
GCA & 4.51 & 0.83 & 0.38 & 0.28 & & \\
GWI & 4.20 & 0.81 & 0.36 & 0.27 & 0.28 & \\
EPS & 4.11 & 0.78 & 0.30 & 0.35 & 0.36 & 0.39 \\
\hline
\end{tabular}

Note: $\mathrm{GTL}=$ Green Transformational Leadership; GA = Green Absorption; GCA = Green Core Affect; GWI = Green Work Intensity; EPS = Environmental Proactive Strategy.

Table 3. Reliability and Validity.

\begin{tabular}{ccc}
\hline Construct & Composite Reliability & Average Variance Extracted \\
\hline GTL & 0.79 & 0.82 \\
GA & 0.78 & 0.79 \\
GCA & 0.76 & 0.80 \\
GWI & 0.80 & 0.79 \\
EPS & 0.76 & 0.79 \\
\hline
\end{tabular}

GTL = Green Transformational Leadership; GA = Green Absorption; GCA = Green Core Affect; GWI = Green Work Intensity; EPS = Environmental Proactive Strategy.

\subsection{The Results of the Analysis}

This work used IBM SPSS Amos 25 to execute the potential growth curve model. The GTL at Time 1 was related to the initial status and increase of EPSs (please see Figure 1). The GTL of CEOs at Time 1 is significantly related to positive changes in corporates' adoption of EPSs $(\beta=0.32, p<0.01)$ (please see Figure 1$)$. Hypothesis 1 that argues that CEOs who exhibit higher levels of GTL at Time 1 cause more positive changes in corporates' adoption of EPSs is supported. That is to say, CEOs exhibit higher levels of GTL at the initial point (Time 1) that has begun to influence corporates to start developing EPSs.

The GTL at Time 1 was related to initial status and increase of green absorption, green core affect, and green work intensity (please see Figure 1). The GTL at the initial point (Time 1) significantly influenced increases in the green absorption $(\beta=0.34, p<0.01)$, green core affect $(\beta=0.32, p<0.01)$, and green work intensity $(\beta=0.32, p<0.01)$ (please see 
Figure 1). Hypothesis 2, Hypothesis 3, and Hypothesis 4 that argue that CEOs who exhibit higher levels of GTL at Time 1 cause more positive changes in green absorption, green core affect, and green work intensity of TMTs are supported. That is to say, CEOs exhibit higher levels of GTL at the initial point (Time 1) that has begun to influence TMTs to start developing green absorption, green core affect, and green work intensity.

The initial status and increase of green absorption, green core affect, and green work intensity were related to the initial status and increase of EPSs (please see Figure 1). Hypothesis 5, Hypothesis 6 and Hypothesis 7 that state that more increases in green absorption $(\beta=0.28, p<0.01)$, green core affect $(\beta=0.22, p<0.01)$, and green work intensity $(\beta=0.28, p<0.01)$ are positively related to more increases in corporates' adoption of EPSs (please see Figure 1) are supported.

\section{Discussion}

This work examined how GTL of CEOs can be related to positive changes of green absorption, green core affect and green work intensity and corporates' adoption of EPSs, and how positive changes of green absorption, green core affect, and green work intensity of TMTs can be related to positive changes of corporates' adoption of EPSs based on upper echelons theory [7].

First, the theoretical contribution of this work is to conceptualize Kahn's (1990) [10] engagement theory as cognitive engagement (green absorption), emotional engagement (green core affect), and physical engagement (work intensity) and proposes the novel concept of green absorption, green core affect and green work intensity. The results of the analysis showed that the green absorption, green core affect, and green work intensity of TMTs are predicted well by the GTL of CEOs at Time 1 and can also predict corporates' adoption of EPSs well, which confirms the validity of GE [45]. Although the linkage between transformational leadership and engagement has been examined in the previous studies $[34,46,47]$, this work added a "green" aspect to activate these variables. It makes sense for EPSs because leaders can employ GTL to transform their followers' engagement with the green aspect, which consequently causes EPSs.

The second theoretical contribution of this work is to open a new stream regarding the GTL of CEOs on corporates' adoption of EPSs. And it is surprising that there is limited research of GTL that is general leadership behavior [35] on corporates' adoption of EPSs. This work proposes the novel concept of GE of TMTs (green absorption, green core affect, and green work intensity) as mediating role to open the black box between GTL of CEOs and corporates' adoption of EPSs. Because past research for enhanced variables on EPSs mainly surveyed the direct effects of organizational factors or social factors [4], this work uses upper echelons theory to propose a new stream on how GTL can influence EPSs by key mediating roles of green absorption, green core affect and green work intensity, which also responds Liu et al.'s (2018) call [8] to dig key mediating roles between characteristics of CEOs and corporates' strategic choices.

The contribution in the practice of this work is to detect effectively enhanced strategies for EPSs. The analysis results showed that the GTL of CEOs can influence positive changes of corporates' adoption of EPSs through the mediating role of GE, and managers should learn how to strengthen these antecedents of EPSs to achieve an environmental performance and competitive advantages. For example, human resources managers generally put a lot of resources into improving a variety of attitudes and practices, it is worth investing resources in leadership training programs [48]. Besides, CEOs should also develop a good working atmosphere that can foster GE of TMTs.

\section{Limitations and Further Research}

The first limitation of this work is to use green absorption, green core affect, and green work intensity to conceptualize GE but there may be other important variables that should be contained in GE. This work leaves it for future studies. Second, there may be other important antecedents of EPSs that should be explored in different environmental contexts. 
For example, green organizational identity [49] of TMTs may be one of the key antecedents of EPSs, because green organizational identity has been confirmed that it can influence corporates' green knowledge sharing, which may influence corporates' EPSs selection opportunities. Future studies should explore a broader range of antecedents for EPSs to provide an incremental contribution. Third, the sample in this work assumes that the samples in the Greater China region are all homogeneous, which may require future research to verify. Fourth, this work proposes the novel concept of green engagement to predict EPSs, but little empirical survey evidence in the past supports the relationship between green engagement and EPSs. Although this work employs upper echelons theory to be the basis reference between green engagement and EPSs, future studies should provide more empirical evidence for the relationship, such as more references and integration discussion of the unique cultural context. Fifth, the data of technology manufacturing businesses of Greater China may restrict the generalization of the analysis results, and future studies should test the theoretical model of this work in different cultural contexts. Sixth, this study employs upper echelons theory to explain the theoretical framework in this study, but the path between GTL and GE can't be explained by upper echelons theory. To supplement the theoretical shortcomings of the theoretical framework in this study, future studies should provide more empirical evidence to support the theoretical framework or explore other theories to explain the theoretical framework in this study. Finally, although this study employs upper echelons theory and power of TMTs to be the inference basis of hypotheses 5 to hypotheses 7 , future studies should provide more empirical literature and empirical evidence to support the hypotheses 5 to 7 .

Author Contributions: Conceptualization, S.Y.B.H. and C.-W.T.; methodology, C.-W.T.; software, C.-W.T.; validation, C.-W.T.; formal analysis, C.-W.T.; investigation, S.Y.B.H. and M.-W.L.; resources, M.-W.L.; data curation, C.-W.T.; writing-original draft preparation, S.Y.B.H.; writing-review and editing, C.-W.T.; visualization, C.-W.T.; supervision, S.Y.B.H.; project administration, S.Y.B.H. and C.-W.T. All authors have read and agreed to the published version of the manuscript.

Funding: This research received no external funding.

Conflicts of Interest: The authors declare no conflict of interest.

\section{References}

1. Brulhart, F.; Gherra, S.; Quelin, B.V. Do Stakeholder Orientation and Environmental Proactivity Impact Firm Profitability? J. Bus. Ethics 2019, 158, 25-46. [CrossRef]

2. Calle, F.; González-Moreno, Á.; Carrasco, I.; Vargas-Vargas, M. Social Economy, Environmental Proactivity, Eco-Innovation and Performance in the Spanish Wine Sector. Sustainability 2020, 12, 5908. [CrossRef]

3. Forés, B. Beyond Gathering the 'Low-Hanging Fruit' of Green Technology for Improved Environmental Performance: An Empirical Examination of the Moderating Effects of Proactive Environmental Management and Business Strategies. Sustainability 2019, 11, 6299. [CrossRef]

4. Dai, J.; Chan, H.K.; Yee, R.W.Y. Examining moderating effect of organizational culture on the relationship between market pressure and corporate environmental strategy. Ind. Mark. Manag. 2018, 74, 227-236. [CrossRef]

5. Li, S.; Qiao, J.; Cui, H.; Wang, S. Realizing the Environmental Benefits of Proactive Environmental Strategy: The Roles of Green Supply Chain Integration and Relational Capability. Sustainability 2020, 12, 2907. [CrossRef]

6. Zhao, J.; Liu, H.; Sun, W. How Proactive Environmental Strategy Facilitates Environmental Reputation: Roles of Green Human Resource Management and Discretionary Slack. Sustainability 2020, 12, 763. [CrossRef]

7. Hambrick, D.C.; Mason, P.A. Upper echelons: The organization as a reflection of its top managers. Acad. Manag. Rev. 1984, 9, 193-206. [CrossRef]

8. Liu, D.; Fisher, G.; Chen, G.L. CEO attributes and firm performance: A sequential mediation process model. Acad. Manag. Ann. 2018, 12, 789-816. [CrossRef]

9. Chen, Y.S.; Chang, C.H. The determinants of green product development performance: Green dynamic capabilities, green transformational leadership, and green creativity. J. Bus. Ethics 2013, 116, 107-119. [CrossRef]

10. Kahn, W.A. Psychological conditions of personal engagement and disengagement at work. Acad. Manag. J. 1990, 33, 692-724.

11. Jenkins, S.; Delbridge, R. Context matters: Examining 'soft' and 'hard' approaches to employee engagement in two workplaces. Int. J. Hum. Resour. Manag. 2013, 24, 2670-2691. [CrossRef]

12. Macey, W.H.; Schneider, B. The meaning of employee engagement. Ind. Organ. Psychol. 2008, 1, 3-30. [CrossRef]

13. Saks, A.M. Antecedents and consequences of employee engagement. J. Manag. Psychol. 2006, 21, 600-619. [CrossRef] 
14. Hambrick, D.C. Upper echelons theory: An update. Acad. Manag. Rev. 2007, 32, 334-343. [CrossRef]

15. Teece, D.J. Explicating dynamic capabilities: The nature and microfoundations of (sustainable) enterprise performance. Strateg. Manag. J. 2007, 28, 1319-1350. [CrossRef]

16. Avolio, B.J.; Bass, B.M. Manual for the Multifactor Leadership Questionnaire (Form 5X); Mind Garden: Redwood City, CA, USA, 2002.

17. Nisar, Q.A.; Zafar, A.; Shoukat, M.; Ikram, M. Green transformational leadership and green performance: The mediating role of green mindfulness and green self-efficacy. Int. J. Manag. Excell. 2017, 9, 1059-1066. [CrossRef]

18. Singh, S.K.; Del Giudice, M.; Chierici, R.; Graziano, D. Green innovation and environmental performance: The role of green transformational leadership and green human resource management. Technol. Forecast. Soc. Chang. 2020, 150, 119762. [CrossRef]

19. Zhou, S.; Zhang, D.; Lyu, C.; Zhang, H. Does Seeing “Mind Acts Upon Mind” Affect Green Psychological Climate and Green Product Development Performance? The Role of Matching Between Green Transformational Leadership and Individual Green Values. Sustainability 2018, 10, 3206. [CrossRef]

20. Yang, D.F.; Wang, A.X.; Zhou, K.Z.; Jiang, W. Environmental strategy, institutional force, and innovation capability: A managerial cognition perspective. J. Bus. Ethics 2019, 159, 1147-1161. [CrossRef]

21. Peng, B.H.; Tu, Y.; Elahi, E.; Wei, G. Extended producer responsibility and corporate performance: Effects of environmental regulation and environmental strategy. J. Environ. Manag. 2018, 218, 181-189. [CrossRef]

22. Sharin, F.H.; Hanafi, M.I.M.; Ahmad, W.A.A.W. Proactive Environmental Strategy and Environmental Performance: The Role of Green Transformational Leadership. Solid State Technol. 2020, 63, 3346.

23. Rothbard, N.P. Enriching or depleting? The dynamics of engagement in work and family roles. Adm. Sci. Q. 2001, 46, 655-684. [CrossRef]

24. Russell, J.A.; Barrett, L.F. Core affect, prototypical emotional episodes, and other things called emotion: Dissecting the elephant. J. Personal. Soc. Psychol. 1999, 76, 805-819. [CrossRef]

25. Brown, S.P.; Leigh, T.W. A new look at psychological climate and its relationship to job involvement, effort, and performance. J. Appl. Psychol. 1996, 81, 358-368. [CrossRef]

26. Shamir, B.; Zakay, E.; Breinin, E.; Popper, M. Correlates of charismatic leader behavior in military units: Subordinates' attitudes, unit characteristics and superiors' appraisal of leader performance. Acad. Manag. J. 1998, 41, 387-409.

27. Bono, J.E.; Judge, T.A. Self-concordance at work: Toward understanding the motivational effects of transformational leaders. Acad. Manag. J. 2003, 46, 554-571.

28. Bakker, A.B.; Demerouti, E. Towards a model of work engagement. Career Dev. Int. 2008, 13, 209-223. [CrossRef]

29. Demerouti, E.; Bakker, A.B. Employee well-being and job performance: Where we stand and where we should go. Occup. Health Psychol. Eur. Perspect. Res. Educ. Pract. 2006, 1, 83-111.

30. Schaufeli, W.B.; Bakker, A.B. The conceptualization and measurement of work engagement. In Work Engagement: A Handbook of Essential Theory and Research; Bakker, A.B., Leiter, M.P., Eds.; Psychology Press: New York, NY, USA, 2010; pp. 10-24.

31. Smircich, L.; Morgan, G. Leadership: The management of meaning. J. Appl. Behav. Sci. 1982, 18, 257-273. [CrossRef]

32. Zhang, W.; Xu, F.; Wang, X. How Green Transformational Leadership Affects Green Creativity: Creative Process Engagement as Intermediary Bond and Green Innovation Strategy as Boundary Spanner. Sustainability 2020, 12, 3841. [CrossRef]

33. Lesener, T.; Gusy, B.; Jochmann, A.; Wolter, C. The drivers of work engagement: A meta-analytic review of longitudinal evidence. Work Stress 2020, 34, 259-278. [CrossRef]

34. Lee, C.-J.; Huang, S.Y.B. A moderated mediation examination of Kahn's theory in the development of new product performance: Cross-level moderating role of open discussion of conflict. Chin. Manag. Stud. 2019, 13, 603-615. [CrossRef]

35. Chen, Y.; Tang, G.; Cooke, F.L.; Jin, J. How does executive strategic resource management link to organizational ambidexterity? an empirical examination of manufacturing firms in China. Hum. Resour. Manag. 2016, 55, 919-943. [CrossRef]

36. Liu, Z.; Li, J.; Zhu, H.; Cai, Z.; Wang, L. Chinese firms' sustainable development-the role of future orientation, environmental commitment, and employee training. Asia Pac. J. Manag. 2014, 31, 195-213. [CrossRef]

37. Podsakoff, P.M.; MacKenzie, S.B.; Lee, J.; Podsakoff, N.P. Common method biases in behavioral research: A critical review of the literature and recommended remedies. J. Appl. Psychol. 2003, 88, 879-903. [CrossRef]

38. Duncan, T.E.; Duncan, S.C.; Strycker, L.A. An Introduction to Latent Variable Growth Curve Modeling: Concepts, Issues, and Applications; Erlbaum: Mahwah, NJ, USA, 2006.

39. Bollen, K.A.; Curran, P.J. Latent Curve Models: A Structural Equation Perspective; Wiley: Hoboken, NJ, USA, 2006.

40. Ng, T.W.H.; Feldman, D.C. The effects of organizational embeddedness on development of social capital and human capital. J. Appl. Psychol. 2010, 95, 696-712. [CrossRef]

41. Ou, A.Y.; Waldman, D.A.; Peterson, S.J. Do humble CEOs matter? An examination of CEO humility and firm outcomes. J. Manag. 2018, 44, 1147-1173. [CrossRef]

42. Brislin, R.W. The wording and translation of research instrument. In Field Methods in Cross-Cultural Research; Lonner, W.J., Berry, J.W., Eds.; Sage: Beverly Hills, CA, USA, 1986; pp. 137-164.

43. Newman, D.A.; Harrison, D.A. Been there, bottled that: Are state and behavioral work engagement new and useful construct "wines"? Ind. Organ. Psychol. 2008, 1, 31-35. [CrossRef]

44. Schaufeli, W.B.; Bakker, A.B. Uwes-Utrecht Work Engagem. Scale Test Man. Dep. Psychol. 2003. Available online: http: //www.schaufeli.com/ (accessed on 1 February 2020).

45. DeVellis, R.F. Scale Development: Theory and Applications; Sage: Thousand Oaks, CA, USA, 2012. 
46. Buil, I.; Martínez, E.; Matute, J. Transformational leadership and employee performance: The role of identification, engagement and proactive personality. Int. J. Hosp. Manag. 2019, 77, 64-75. [CrossRef]

47. Li, H.; Sajjad, N.; Wang, Q.; Muhammad Ali, A.; Khaqan, Z.; Amina, S. Influence of Transformational Leadership on Employees' Innovative Work Behavior in Sustainable Organizations: Test of Mediation and Moderation Processes. Sustainability 2019, 11, 1594. [CrossRef]

48. Sadowski, B.; Cantrell, S.; Barelski, A.; O’Malley, P.G.; Hartzell, J.D. Leadership training in graduate medical education: A systematic review. J. Grad. Med. Educ. 2018, 10, 134-148. [CrossRef] [PubMed]

49. Chang, T.-W.; Hung, C.-Z. How to Shape the Employees' Organization Sustainable Green Knowledge Sharing: Cross-Level Effect of Green Organizational Identity Effect on Green Management Behavior and Performance of Members. Sustainability 2021, 13, 626. [CrossRef] 